Chirurgia (2018) 113: 593-602

No. 5, September - October

Copyright $\odot$ Celsius

http://dx.doi.org/10.21614/chirurgia.113.5.593

\title{
Acute Abdomen in Diabetic Patients - What Should We Do?
}

\author{
Horia Doran, Traian Pătrașcu \\ “Carol Davila” University of Medicine and Pharmacy, "Dr. I. Cantacuzino” Clinical Hospital, 1st Surgical Department, Bucharest, Romania
}

Corresponding author:

Associate Professor Horia Doran

"Carol Davila" University

of Medicine and Pharmacy

"Dr. I. Cantacuzino" Clinical Hospital

$1^{\text {st }}$ Surgical Department

Bucharest, Romania

E-mail: doranh2003@yahoo.com

\section{Rezumat}

Abdomenul acut la diabetici - ce e de făcut?

Diabetul zaharat este o afecțiune metabolică bine cunoscută, a cărei incidență este în creştere în întreaga lume. Particularitățile anatomo-patologice şi clinice ale multor afecțiuni, inclusiv ale abdomenului acut, sunt modificate semnificativ la pacientii diabetici, ceea ce impune o strategie terapeutică nuanțată. In principal, două atitudini pot fi eronate, ambele cu efect negativ asupra evolutiei pacienților: o intervenție chirurgicală întârziată în cazul unei peritonite, datorită aspectului său clinic şi biologic atipic, sau o laparotomie inutilă la un pacient diabetic cu cetoacidoză, ceea ce va agrava suplimentar o stare generală precară. De aceea, pentru a evita confuziile şi erorile diagnostice, utilizarea frecventă a tehnicilor imagistice avansate (TC, RMN) sau explorarea laparoscopică a cavității peritoneale se pot dovedi necesare în multe situații.

Cuvinte cheie: abdomen acut, ceto-acidoză diabetică

\section{Abstract}

Diabetes mellitus is a well-known metabolic disease, with an increasing incidence around the world. The histological and clinical features of many diseases, including acute abdomen, are significantly modified in diabetic patients and thus the therapeutic approach should be carefully considered. Two main errors are possible, and they may equally cause a poor outcome of the patient: a delayed surgical procedure in peritonitis, due to its atypical clinical and biological expression, or an un-necessary laparotomy in 
a diabetic patient with acidosis, which transforms an already severe condition into a worse one. Therefore, in order to avoid confusion of diagnosis and treatment, the extended use of advanced imaging techniques (CT, MRI) or even a laparoscopic inspection of the peritoneal cavity may proove justified in many cases.

Key words: acute abdomen, diabetic ketoacidosis

\section{Background}

Diabetes mellitus is considered to be one of the most challenging health problems of the $21^{\text {st }}$ century (1). Worldwide, it was estimated that there were 415 million diabetic patients aged 20-79 years in 2015, and the number was predicted to rise to 642 million by 2040. In Germany, diabetes was diagnosed in $7.2 \%$ of the adults $(7.4 \%$ of the women; $7.0 \%$ of the men) and its prevalence increased substantially with advancing age and in persons of low, rather than high socioeconomic status (2). In our country, higher rates should be expected, although the number of un-diagnosed patients could be difficult to estimate.

Diabetes has a large variety of well-known vascular complications, including retinopathy, nephropathy and cardiovascular disease. Autonomic neuropathy is less obvious, but it may generate confusing clinical features in diabetic patients with acute abdomen; therefore, the diagnosis and the surgical treatment can be significantly delayed.

The autonomic nervous system innervates the entire human body, and is involved in the regulation of every single organ. Perturbations in autonomic function account for everything from abnormalities in pupillary function to gastroparesis, intestinal dysmotility, diabetic diarrhea, genitourinary dysfunction. Autonomic dysfunction can affect the daily activities of individuals with diabetes and may lead to potentially life-threatening outcomes. Its prevalence increases with age, duration of diabetes, obesity, smoking and poor glycemic control. Diabetic neuropathy usually co-exists with microangiopathy and macroangiopathy; moreover, their effects are synergic (3).

\section{Material and Methods}

The Surgical Clinic of "Dr. I. Cantacuzino" Clinical Hospital has a wide experience in the management of diabetic patients with abdominal surgical pathology, due to the proximity of "N.Paulescu" National Institute of Diabetes and Metabolic Diseases and to the expertise of its medical staff. Every year, around 3200 patients are admitted and operated in our clinic, almost $20 \%$ of which also have diabetes mellitus.

Imaging procedures include abdominal $\mathrm{X}$-ray and ultrasonography, CT-scan or MRI in selected cases. In case of persisting doubt, the diagnosis is usually confirmed or disproved by a laparoscopic inspection of the peritoneal cavity, which also allows a minimally invasive approach to the cause of peritonitis.

\section{Results}

\section{Acute appendicitis}

Acute appendicitis is the most common surgical disease and appendectomy is still considered the treatment of choice in the majority of cases. A correct diagnosis is key for decreasing the superfluous appendectomy rate, but the management can become difficult in cases of complicated appendicitis (4). There is a consensus that a history of diabetes is an important factor with regard to the rate of acute and perforated appendicitis (5). However, the diagnosis is often difficult, due to the peculiar reactivity of these patients. First of all, the classical symptoms of acute appendicitis are well-known: anorexia, nausea and vomiting and, sometimes, constipation. Unfortunately, 
they are not specific at all and, in diabetic patients, they can be easily correlated to diabetic autonomic neuropathy, which may accelerate or slow down the intestinal transit.

The intensity of the pain, which is the most important clinical sign, may be significantly decreased due to the same neuropathy and it may not reflect the rapid evolution of the inflammatory process. We have operated several cases of acute phlegmonous or even gangrenous appendicitis in which the pain had been described as mild or moderate. Furthermore, the physical signs were not very obvious; we rarely found direct tenderness and muscle spasm in the right lower quadrant.

The main biological finding is expected to be leukocytosis. However, the deficiencies of immune reactions in diabetic patients cause a smooth and delayed elevation of leucocyte count; thus, quasi-normal ranges of 10,000$12,000 / \mathrm{mm}^{3}$ are not very surprising in severe forms of acute appendicitis. At the same time, high values of $15,000-20,000 / \mathrm{mm}^{3}$ should be considered very alarming and, in the appropriate clinical situation, should strongly mandate a laparotomy or laparoscopy in emergency.

Abdominal ultrasonography is more useful for the diagnosis, as it is not affected by the particularities of diabetic patients. The presence of abdominal fluids in the right iliac fossa and the distension of the appendix are significant findings, as well as a normal view of internal genitalia, in female patients. An upright abdominal radiograph may demonstrate a fecalith, localized ileus or, rarely, pneumoperitoneum. The diagnostic accuracy of MR imaging is appreciated as similar to that of $\mathrm{CT}$ for the diagnosis of acute appendicitis (6).

Diagnostic laparoscopy may represent the ultimate solution, in patients in whom appendicitis cannot be ruled out, as it also allows a minimally invasive appendectomy. However, a normal appendix should be left in place, although there is no consensus on this and some authors recommend its removal.

In diabetic patients, metabolic disorders are often caused by septic episodes; respiratory, abdominal or urinary infections may be the cause of unstable blood glucose level, which cannot be corrected. We emphasize the fact that in diabetic patients with unexplained hyperglycemia and ketoacidosis, the initial physiopathological factor may very well be sepsis; clinical, biological and, most of all, imaging investigations should therefore be focused on locating the initial process.

Although the indication of surgical treatment for acute appendicitis has been considered self-evident for many decades, the development of antibiotics has challenged this attitude and many studies have reported encouraging results after this kind of "conservative" treatment. However, the initial enthusiasm has diminished and nowadays there seems to be a consensus regarding the fact that appendectomy remains the most effective treatment even for patients with uncomplicated acute appendicitis, due to its significantly higher efficacy and low complication rate (7). Furthermore, a study of the patients' preferences regarding surgical compared to nonsurgical therapy has shown that most patients may prefer a surgical approach over a strictly pharmacological one (8).

In diabetic patients, the choice of nonsurgical treatment raises important concerns, as the evolution towards severe histological forms may be very rapid, while the clinical and biological findings do not entirely reflect the severity of the peritoneal involvement and of the septic process. Many studies proved that diabetic patients have a higher risk for recurrent appendicitis after antibiotic treatment during a 1-year follow-up period than nondiabetic patients using population-based database (9). Therefore, we consider that in acute appendicitis, as well as in cases with persisting doubt, classical or laparoscopic exploration and appendectomy should be performed (10). If the appendix is normal, appendectomy should be avoided, as it involves a "septic moment" and does not seem to have any short or long-time benefits.

\section{Acute Cholecistitis}

Cholelithiasis and acute calculous cholecystitis 
have higher prevalence in the diabetic population, due to the defects in gallbladder motility caused by autonomic neuropathy, which allow and favour crystal precipitation and to the metabolic disorders which are common in these patients. Both mechanisms play a central role in the pathogenesis of gallstones.

The local complications are represented by the visceral mass present in the right upper quadrant (gallbladder with greater omentum), but mainly by the abscesses of the inferior surface of the liver, which are responsible for sepsis.

The clinical diagnosis of acute cholecystitis in diabetic patients has similar features to that of acute appendicitis: physical examination and biological findings are usually subtle and delayed, while the pathological process rapidly worsens and evolves towards gangrene (11). Leucocyte count is not very helpful either, and therefore the positive diagnosis is based on imaging techniques. Abdominal ultrasonography is quite sensitive and it also has the advantages of being largely available and affordable: it shows the presence and the size of gallstones, the gallbladder wall thickening and also the pericholecystic fluid. Computed tomography is obviously more sensitive, but less accessible, while MRIcholangiography is the "gold-standard" for the exploration of biliary ducts.

The treatment of acute cholecystitis consists of laparoscopic cholecystectomy, performed as soon as the diagnosis has been confirmed. Patients with diabetes who undergo cholecystectomy 24 hours or more after admission, due to a delayed diagnosis, are expected to have an increased risk of postoperative surgical-site infection and a longer hospital stay than those undergoing surgery within 24 hours of admission (12). Another important issue is that conversion may occur in a significant number of cases. In several studies, age over 65 years, diabetes and CRP over $150 \mathrm{mg} / \mathrm{l}$ were identified as independent preoperative risk factors for conversion. Complications of severe inflammation like gangrene of the gallbladder and an abscess identified by the surgeon (and which are not rare in diabetic patients) were also recognized as risk factors in the multivariate analysis examining both preoperative and intraoperative findings $(13,14)$.

The postoperative evolution is also less favorable. In patients undergoing cholecystectomy for acute cholecystitis, diabetes increases the risk of mortality, cardiovascular events, and renal failure. Insulin-treated diabetics have more co-morbidities and poorer outcomes (15).

A peculiar situation, with a higher prevalence in diabetic patients, is represented by the acute acalculous cholecystitis, defined by ultrasonographic, intraoperative and pathologic findings of acute cholecystitis, without evidence of gallstones. It is associated to recent operations, trauma, burns, multisystem organ failure and parenteral nutrition. It may also occur in the absence of an obvious trigger, in patients with pathological conditions which generate local ischemia, like diabetes mellitus, malignant disease, abdominal vasculitis, or congestive heart failure (16).

Acute acalculous cholecystitis is mainly caused by ischemia. The arteriography of specimens showed arterial dilatation and extensive venous filling in acute gallstoneassociated cholecystitis. On the other hand, multiple arterial occlusions, with absent or minimal venous filling, were consistent features of acute acalculous cholecystitis; the degree of arteriographic abnormality in these cases corresponded with the severity of gallbladder pathologic findings. The conclusion was that small vessel occlusion, on the basis of low splanchnic flow or intravascular coagulation, may be a fundamental element in the pathogenesis of acute acalculous cholecystitis (17).

Abdominal ultrasonography and computed tomography should settle the diagnosis, based on the presence or absence of edema and thickening of the gallbladder wall and on the intraperitoneal, pericholecystic fluid. The main pathological finding is represented by the gangrene of the gallbladder mucosa, correlated to the degree of ischemia, but also to the delaying diagnosis and treatment (Fig. 1).

The therapeutic approach is emergency surgery and the best procedure in diabetic 


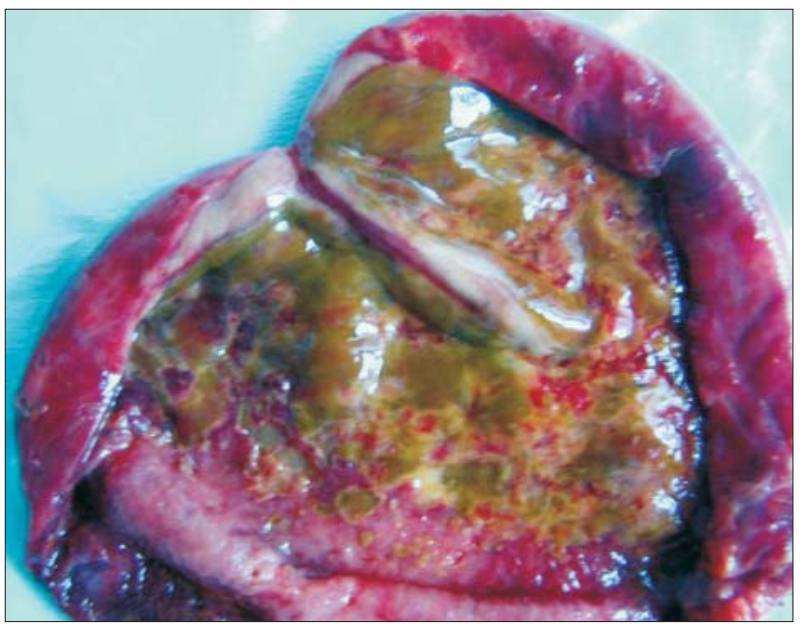

Figure 1. Gangrene of the gallbladder mucosa (specimen)

patients seems to be laparoscopic cholecystectomy. In critically ill patients with sepsis, the treatment is not well defined, and there is only limited evidence about whether percutaneous drainage or cholecystectomy is preferred (18).

The outcome of these patients seems to be quite poor; the mortality after postoperative acute ischemic cholecystitis (in critically ill patients) is as high as $23-40 \%$. The mortality of elderly patients tends to be higher and diabetes mellitus may also increase the risk of death (18).

\section{Acute Pancreatitis}

In diabetic patients, acute pancreatitis has a higher prevalence and severity, due to the importance of metabolic factors. Furthermore, the involvement of the pancreas, which is the core of the glucidic metabolism, causes significant disorders, such as hyperglycemia and ketoacidosis. Traditionally, it was believed that disturbances in carbohydrate metabolism could result from acute stress, pancreatic microcirculation disorder and excessive secretion of catecholamine after acute pancreatitis, leading to transient elevations in blood glucose. After the treatment of the acute episode, the blood glucose should soon return to normal. However, some of these patients may not fully recover from the hyperglycemia and their blood glucose could rise again after a short term recovery; afterwards, they may develop diabetes mellitus and need treatment with antidiabetic medication or insulin in their rest of lives (19). There has been described a type $3 c$ diabetes mellitus, which is determined by pancreatic destruction during one or more episodes of acute pancreatitis. This type of diabetes is a clinically revealing condition with a prevalence of 5-10\% among all diabetic subjects in Western populations. Its frequency and clinical importance have been underestimated so far. Its complexity is increased by comorbidities, such as maldigestion and concomitant qualitative malnutrition (20). Some papers also named it "diabetes following pancreatic disease" or "diabetes of the exocrine pancreas" and found out that it is frequently labeled as type 2 diabetes, but has worse glycemic control and a markedly greater insulin requirement (21).

The clinical findings in acute pancreatitis may be miscellaneous, as the physical and biological findings of metabolic disorders are quite obvious, while the abdominal signs are not very specific; they tend to be rather subtle and delayed. Therefore, treating the underlying trigger during diabetic crises is just as important as managing metabolic disturbances in order to achieve favorable outcomes; meanwhile, managing acute pancreatitis-associated hyperglycemia can promote recovery (22).

A peculiar case is represented by the so-called "metabolic acute pancreatitis", prompted by the association between hypertriglyceridemia and induced acute pancreatitis, with diabetic ketoacidosis. These pathologic conditions are interconnected, as some authors appreciate that severe hypertriglyceridemia, as well as diabetic ketoacidosis are in fact complications of type 1 diabetes (23). The positive diagnosis of acute pancreatitis in these cases presents with many challenges. First, epigastric pain is quite common during episodes of diabetic ketoacidosis, and onefourth of these patients have elevated levels of serum lipase and amylase without any clinical or radiological evidence of pancreatitis. A three-fold rise in serum lipase and amylase levels is considered specific for the diagnosis of 
acute pancreatitis, but in the hypertriglyceridemia-induced form, the enzyme levels can remain normal. Almost 50\% cases of these patients have normal levels of amylase due to lipemic content of blood, which interferes with the calorimetric assay of amylase and the presence of inhibitors of assay in plasma. Acute pancreatitis with diabetic ketoacidosis and normal levels of serum lipase have been also described (24).

The positive diagnosis is therefore based on imaging methods (CT or MRI), which should follow the dynamic evolution of the inflammatory and necrotizing process (Fig. 2). In addition to assessment of relevant clinical and biochemical parameters, computed tomography scanning has been considered for a long time the reference standard not only for diagnostic purposes, but also for assessing the severity of acute pancreatitis. The enhanced CT severity index (CTSI) and the unenhanced Balthazar score are the most widely used CT scoring systems. However, some investigators have suggested that CT scanning on admission is not relevant, because it takes a few days for pancreatic necrosis to develop, and CT scans obtained in the early phase of the disease would not change clinical management. They have also recommended that CT studies should be reserved only for those patients with significant likelihood of severe acute pancreatitis. Moreover, the use of contrast agents may worsen the course of the pancreatitis (25).

MRI is useful for its possible findings of hemorrhage in acute pancreatitis and for correlating the presence and extent of hemorrhage with the MR severity index (MRSI), Acute Physiology And Chronic Health Evaluation (APACHE) II scores, and clinical outcome. The presence of hemorrhage, rather than its extent, correlates with poor clinical outcome (26).

The therapeutic approach follows the classical "no needles, no knives" rule. The European Society of Gastrointestinal Endoscopy (ESGE) has recently (May 2018) published an evidence-based multidisciplinary guideline. It strongly recommended:

- initial goal-directed intravenous fluid

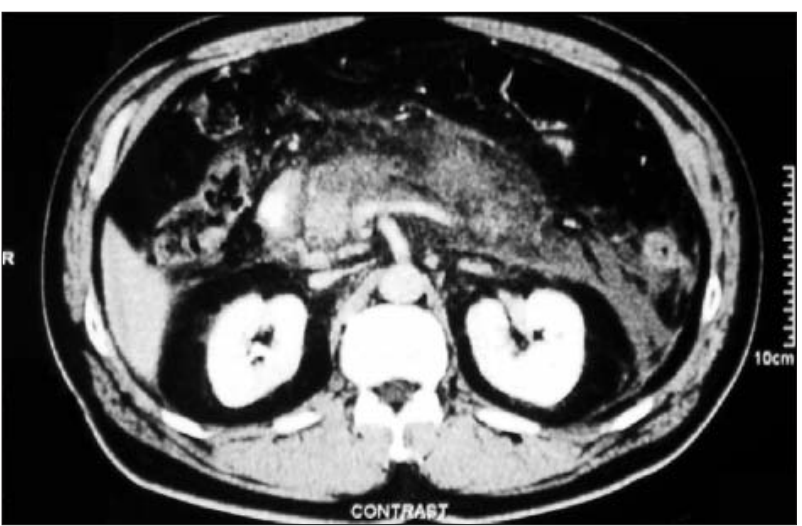

Figure 2. Acute necrotizing pancreatitis (CT scan)

therapy with Ringer's lactate (e.g. 5-10 $\mathrm{mL} / \mathrm{kg} / \mathrm{h}$ ) at onset; then, fluid requirements - patient-tailored and reassessed at frequent intervals;

- against antibiotic or probiotic prophylaxis of infectious complications in acute necrotizing pancreatitis;

- performing endoscopic or percutaneous drainage of infected walled-off necrosis as the first interventional method;

- long-term indwelling of transluminal plastic stents in patients with disconnected pancreatic duct syndrome;

- invasive intervention for patients with acute necrotizing pancreatitis and clinically suspected or proven infected necrosis (27).

The therapeutic attitude towards pancreatic pseudocysts following acute pancreatitis has also changed. Conservative expectant management may be possible in up to $40 \%$ of all pancreatic pseudocysts which is why conservative treatment should be continued for more than 6 weeks in asymptomatic patients with pancreatic pseudocysts. The size and persistance of the pancreatic pseudocysts should no longer be considered as the prime indicators for surgical intervention (28). Indications for abandoning conservative treatment are: persistent pain, gastric outlet obstruction, weight loss, jaundice, dyspepsia. In those cases which require surgical procedures, endoscopic drainage is becoming the preferred therapeutic approach because it is less invasive than 
surgery and has higher long-term success rate. The options are represented by: transpapillary approach with ERCP (which is preferablewhen the pseudocyst communicates with the main pancreatic duct), direct drainage across the stomach or duodenal wall, or EUS guided transmural stenting (29).

\section{Acute Intestinal Infarction}

The main cause involved in the pathophysiology of acute mesenteric ischemia and of intestinal infarction is the co-existence of obstruction on both large and small vessels, which is a common finding in diabetic, elderly patients. The diagnosis is usually a difficult one, as there are no specific physical, biological or imaging signs. Consequently, the time span for vascular surgery is often overpassed and the viability of the intestinal loops is compromised. The existence of intestinal necrosis may be assumed before the beginning of the surgical procedure, but in most of the cases the positive diagnosis is intra-operative (Fig. 3).

There have been contradictory discussions regarding short bowel syndrome following large intestinal excisions. Progress has been made in the understanding of intestinal adaptation, characterized by improvements in intestinal absorption, changes in hormonal secretion, development of hyperphagia and dysbiosis of the gut microbiota (30). These changes may explain why patients who have had a length of 30-40 cm of remaining bowel

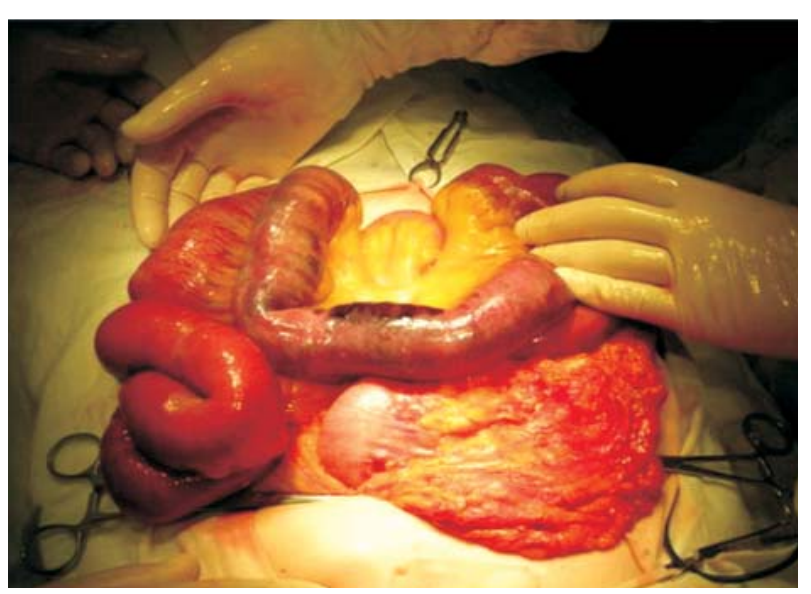

Figure.3. Intestinal necrosis (intra-operative view) have surprisingly survived, in a satisfactory physical and metabolic condition.

Therefore, our therapeutic approach in large intestinal infarction, with intestinal loop necrosis, has significantly evolved; in these cases, we usually perform a large excision of the small bowel, as extensive as necessary, and an ileostomy. We have avoided primary anastomosis, as the vascular status is often poor, while the co-existence of occlusion and peritonitis in elderly patients represented one of the worst possible combinations. The outcome has been favorable in many cases and, in some of them, restoring the intestinal continuity has become possible afterwards. Long-term management of the short bowel syndrome required a coordinated approach including dietary and fluid modifications, symptombased conventional medication, selective use of intestinotrophic agents and surgery, and management of preexisting conditions, ideally by a multidisciplinary team (31).

Encouraging results, confirmed by several studies, were obtained with Teduglutide, a recombined, degradation-resistant, longeracting analogue of Glucagon-Like Peptide-2. GLP-2 induces gut epithelial proliferation by stimulating crypt cell proliferation and inhibiting enterocyte apoptosis, increases absorptive capacity and inhibits gut motility and secretion (32).

\section{Primary Peritonitis}

Primary peritonitis or spontaneous peritonitis is classically defined as the presence of pathogenic bacteria inside the peritoneum, without any breach in the peritoneal layer. The main mechanism involved appears to be bacterial translocation, while the most frequent germs are E coli and Klebsiella pneumonia. Primary peritonitis appears in immunodeficient patients, which explains their higher prevalence in the diabetic population.

The positive diagnosis cannot be settled before the procedure, as there are no specific clinical, biological or imaging signs available. However, serum procalcitonin is significantly higher, which justifies its use as a primary 
marker for peritonitis. The usefulness of peritonitic fluid procalcitonin to diagnose primary peritonitis has not been demonstrated (33). Laparoscopic exploration of the peritoneal cavity is the best possible option, as it may exclude a perforation as the cause of a secondary peritonitis and it also allows the bacteriological analysis of the peritoneal liquid. In primary peritonitis, a polymorphonuclear cell count of more than 250 cells $/ \mathrm{mm}^{3}$ in the peritoneal fluid and a single type of bacteria, usually Gram positive cocci, are found.

Empirical antibiotic treatment has to be initiated immediately after the diagnosis of primary peritonitis. Third-generation cephalosporins have been the most frequently used antibiotics since 1985 and were highly effective until about 10 year ago, but the emergence of resistance to them is of great concern. Following evaluation of antibiotic susceptibility in several series of cases, some studies recommended the use of cefoperazone/sulbactam or piperacillin/ tazobactam (34), while others reported better results after the use of cefepime, a fourthgeneration cephalosporin with good activity against most nosocomial Gram-negative bacteria and Gram-positive cocci (35).

\section{Diabetic Ketoacidosis and the Acute Abdomen}

Diabetic ketoacidosis is a severe metabolic emergency condition, which is characterized by hyperglycemia, metabolic acidosis and ketonemia. It is the result of absolute or relative insulin deficiency, mostly in type 1 diabetes mellitus, but it can also occur in type 2 diabetes. Ketoacidosis is frequently associated with abdominal pain, particularly if the degree of acidosis is severe, so it may suggest a false diagnosis of acute abdomen. According to several studies, abdominal pain and tenderness are common in patients with severe ketoacidosis, with a plasma bicarbonate level of $\leq 10 \mathrm{mEq} / \mathrm{L}$ (36).

The pathogenesis of abdominal pain in diabetic ketoacidosis varies, but severe hyperlipidemia is an identifiable causative factor. However, the massive accumulation of triglycerides interferes with the measurement of biochemical values and results in normal or even low levels of electrolytes. In fact, even glucose concentrations can appear falsely low in the presence of hypertriglyceridemia; therefore, the diagnosis and treatment of ketoacidosis may be delayed due to pseudonormoglycemia in the presence of massively elevated serum triglyceride levels (37).

The dilemma of an accurate and rapid diagnosis is increased by the fact that acute abdominal conditions, mainly peritonitis, are often themselves the cause of metabolic disorders, with hyperglycemia and ketoacidosis. Therefore, diabetic ketoacidosis may be: the cause of abdominal pain (thought to be the sign of peritonitis) or the effect of a real secondary bacterial peritonitis, which causes abdominal pain.

In the first case, the therapeutic approach is conservative and a surgical procedure is useless and even dangerous, as anesthesia and surgery would only increase the severity of metabolic aggression and the intensity of metabolic disorders. In the second case, the operation is mandatory, as the only available life-saving treatment.

This is the reason why the co-existence of intense abdominal pain and diabetic ketoacidosis should be carefully analyzed, in order to understand the appropriate cause and effect sequence. Clinical and even biological signs are not specific, as a higher leucocyte count and inflammatory markers are common findings in many pathological conditions which may occur in diabetic patients. Imaging techniques (abdominal ultrasonography, computed tomography or MRI) should provide valuable data in order to settle a positive diagnosis. In case of persisting doubt, the laparoscopic exploration of the peritoneal cavity seems to remain the best option, in order to avoid an even greater error- a further delay in the diagnosis and the surgical treatment of a secondary peritonitis in a diabetic patient with severe metabolic disorders (38).

\section{Conclusion}

The diagnosis and treatment of acute abdomen 
in diabetic patients may pose a challenge, even for experienced surgeons. The evolution of the lesions towards severe pathological forms is rapid, due to the immune deficiencies of these patients. However, the clinical and biological findings may not be correlated to the severity of the septic process. Unexplained hyperglycemia and metabolic disorders which are difficult to manage may be the only signs which somehow suggest the existence of an inflammatory or septic condition. Imaging methods are widely indicated in order to settle the diagnosis and the indication for emergency surgery.

The association between abdominal pain and hyperglycemia with ketoacidosis may be even more confusing. Acute abdomen, especially peritonitis is characterized by severe abdominal pain, but can also generate metabolic disorders and ketoacidosis. Nevertheless, diabetic ketoacidosis often generates abdominal pain itself, which may be misinterpreted as a sign of peritonitis. Therefore, an accurate diagnosis is of outstanding importance, because the treatment differs significantly: peritonitis imposes an emergency surgical procedure, as the only possible life-saving approach. On the contrary, diabetic ketoacidosis has to be treated with medical methods; in this case, anesthesia and an operation would worsen an already severe condition. Advanced imaging methods, like computed tomography or MRI should provide the correct answer. In case of persisting doubt, an exploratory laparoscopy seems to be the lesser of two evils.

\section{Acknowledgements}

The authors would like to thank Cristina Doran for her assistance in English translation.

\section{Disclosures}

The authors have no conflicts of interest or financial ties to disclose.

\section{References}

1. International Diabetes Federation. IDF Diabetes Atlas. 6th ed.
Brussels: International Diabetes Federation; 2013.

2. Bächle C, Claessen H, Maier W, Tamayo T, Schunk M, RückertEheberg IM, et al. Regional differences in antihyperglycemic medication are not explained by individual socio-economic status, regional deprivation, and regional health care services. Observational results from the German DIAB-CORE consortium. PLOS One. 2018;13(1):e0191559.

3. Vinik Al, Erbas T. Diabetic autonomic neuropathy. Handb Clin Neurol. 2013;117:279-94.

4. Sartelli M, Baiocchi GL, Di Saverio S, Ferrara F, Labricciosa FM, Ansaloni $\mathrm{L}$, et al. Prospective Observational Study on acute Appendicitis Worldwide (POSAW). World J Emerg Surg. 2018;13:19.

5. Wei PL, Lin HC, Kao LT, Chen YH, Lee CZ. Diabetes is associated with perforated appendicitis: evidence from a population-based study. Am J Surg. 2016;212(4):735-739.

6. Repplinger MD, Pickhardt PJ, Robbins JB, Kitchin DR, Ziemlewicz TJ, Hetzel SJ, et al. Prospective comparison of the diagnostic accuracy of MR imaging versus CT for acute appendicitis. Radiology. 2018;288(2):467-475.

7. Podda M, Cillara N, Di Saverio S, Lai A, Feroci F, Luridiana G, et al. Antibiotics-first strategy for uncomplicated acute appendicitis in adults is associated with increased rates of peritonitis at surgery. A systematic review with meta-analysis of randomized controlled trials comparing appendectomy and non-operative management with antibiotics.- Surgeon. 2017;15(5):303-314.

8. Hanson AL, Crossby RD, Masson MD. Patient Preferences for Surgery or Antibiotics for the Treatment of Acute Appendicitis. JAMA Surg. 2018;153(5):471-478.

9. Tsai MC, Lin HC, Lee CZ. Diabetes increases the risk of an appendectomy in patients with antibiotic treatment of noncomplicated appendicitis. Am J Surg. 2017;214(1):24-28.

10. Pătrașcu T, Doran H, Mihalache 0 , Bobircă F. Acute appendicitis and empiric antibiotic therapy. Chirurgia (Bucur). 2010;105(3): 399-402. Romanian

11. Bourikian S, Anand RJ, Aboutanos M, Wolfe LG, Ferrada P. Risk factors for acute gangrenous cholecystitis in emergency general surgery patients. Am J Surg. 2015;210(4):730-3.

12. Gelbard R, Karamanos E, Teixeira PG, Beale E, Talving P, Inaba K, et al. Effect of delaying same-admission cholecystectomy on outcomes in patients with diabetes. Br J Surg. 2014;101(2):74-8.

13. Terho PM, Lappaniemi AK, Mentula PJ. Laparoscopic cholecystectomy for acute calculous cholecystitis: a retrospective study assessing risk factors for conversion and complications. World $\mathrm{J}$ Emerg Surg. 2016 Nov 16;11:54. eCollection 2016.

14. Yang TF, Guo L, Wang $Q$. Evaluation of preoperative risk factor for converting laparoscopic to open cholecystectomy: A meta-analysis. Hepatogastroenterology. 2014;61(132):958-65.

15. Karamanos E, Sivrikoz E, Beale E, Chan L, Inaba K, Demetriades D. Effect of diabetes on outcomes in patients undergoing emergent cholecystectomy for acute cholecystitis. World J Surg. 2013; 37(10):2257-64.

16. Doran H, Mihalache 0 , Bobircă F, Bugă C, Pătrașcu T. Acute acalculous cholecystitis - difficulties of diagnosis and treatment. Chirurgia (Bucur). 2010;105(4):465-8. Romanian

17. Warren BL. Small vessel occlusion in acute acalculous cholecystitis. Surgery. 1992;111(2):163-8.

18. Liu FL, Li H, Wang XF, Shen KT, Shen ZB, Sun YH, et al. Acute acalculous cholecystitis immediately after gastric operation: Case report and literatures review. World J Gastroenterol. 2014;20(30): 10642-50.

19. Tu J, Zhang J, Ke L, Yang Y, Yang Q, Lu G, et al. Endocrine and exocrine pancreatic insufficiency after acute pancreatitis: long-term follow-up study. BMC Gastroenterol. 2017;17(1):114.

20. Ewald N, Bretzel RG. Diabetes mellitus secondary to pancreatic diseases (Type 3c)--are we neglecting an important disease? Eur J Intern Med. 2013;24(3):203-6.

21. Woodmansey C, McGovern AP, McCullough KA, Whyte MB, Munro 
NM, Correa AC, et al. Incidence, demographics, and clinical characteristics of diabetes of the exocrine pancreas (Type 3c): a retrospective cohort study. Diabetes Care. 2017;40(11):1486-1493.

22. Song $\mathrm{R}$, Cao S. Prediabetes directly deteriorates into diabetic ketoacidosis and hyperosmolar hyperglycemic syndrome triggered by acute pancreatitis: a case report illustrating a "chicken and egg" paradigm in ketosis-prone diabetes. Diabetes Ther. 2018 9(3):1377-1383

23. Fick T, Jack J, Pyle-Eilola AL, Henry RK. Severe hypertriglyceridemia at new onset type 1 diabetes mellitus. J Pediatr Endocrinol Metab. 2017;30(8):893-897.

24. Kumar P, Sakwariya A, Sultania AR, Dabas R. Hypertriglyceridemiainduced acute pancreatitis with diabetic ketoacidosis: A rare presentation of type 1 diabetes mellitus. J Lab Physicians. 2017; 9(4):329-331.

25. Chen C, Huang Z, Li H, Song B, Yuan F. Evaluation of extrapancreatic inflammation on abdominal computed tomography as an early predictor of organ failure in acute pancreatitis as defined by the revised Atlanta classification. Medicine (Baltimore). 2017; 96(15):e6517.

26. Tang MY, Chen TW, Bollen TL, Wang YX, Xue HD, Jin ZY, et al. MR imaging of hemorrhage associated with acute pancreatitis. Pancreatology. 2018;18(4):363-369.

27. Arvanitakis M, Dumonceau JM, Albert J, Badaoui A, Bali MA Barthet $\mathrm{M}$, et al. Endoscopic management of acute necrotizing pancreatitis: European Society of Gastrointestinal Endoscopy (ESGE) evidence-based multidisciplinary guidelines. Endoscopy. 2018; 50(5):524-546.

28. Cheruvu CV, Clarke MG, Prentice M, Eyre-Brook IA. Conservative treatment as an option in the management of pancreatic pseudocyst. Ann R Coll Surg Engl. 2003;85(5):313-6.
29. Agalianos C, Passas I, Sideris I, Davides D, Dervenis C. Review of management options for pancreatic pseudocysts. Transl Gastroenterol Hepatol. 2018;3:18.

30. Billiauws L, Corcos 0 , Joly $F$. What's new in short bowel syndrome? Curr Opin Clin Nutr Metab Care. 2018;21(4):313-318.

31. Parrish KR, DiBaise JK- Managing the Adult Patient With Short Bowel Syndrome. Gastroenterol Hepatol (N Y). 2017;13(10):600-608.

32. Lam K, Schwartz L, Batisti J, Iyer KR. Single-Center experience with the use of teduglutide in adult patients with short bowel syndrome. JPEN J Parenter Enteral Nutr. 2018;42(1):225-230.

33. Shizuma T. Spontaneous bacterial and fungal peritonitis in patients with liver cirrhosis: a literature review. World J Hepatol. 2018; 10(2):254-266

34. Shi L, Wu D, Wei L, Liu S, Zhao P, Tu B, et al. Corrigendum: nosocomial and community-acquired spontaneous bacterial peritonitis in patients with liver cirrhosis in China: comparative microbiology and therapeutic implications. Sci Rep. 2017;7:46868.

35. Jindal A, Kumar M, Bhadoria AS, Maiwall R, Sarin SK. A randomized open label study of 'imipenem vs. cefepime' in spontaneous bacterial peritonitis. Liver Int. 2016;36(5):677-87.

36. Fujishiro M, Horita A, Nakagawara $H$, Mawatari T, Kishigami $Y$, Tominaga $Y$, et al. Severe hypertriglyceridemia possibly masked acute pancreatitis and led to a difficult diagnosis in an obese patient with ketoacidosis-onset type 2 diabetes. Intern Med. 2017;56(19): 2611-2616.

37. Kaminska ES, Pourmotabbed G. Spurious laboratory values in diabetic ketoacidosis and hyperlipidemia. Am J Emerg Med. 1993; 11(1):77-80.

38. Doran H, Pătrașcu Tr. Afecțiunile abdominale acute la bolnavul diabetic. Bucuresti: Ed.Niculescu; 2012. p. 127-138. 